\title{
Analysis of $\mathrm{FM} / \mathrm{M}(\mathrm{a}, \mathrm{b}) / 1 / \mathrm{MWV} / \mathrm{Br}$ Queueing Model
}

\author{
K. Julia Rose Mary, PhD \\ Asso.Prof of Mathematics \\ Nirmala College for Women \\ Coimbatore-18
}

\author{
R. Rajalakshmi \\ M.Sc Mathematics \\ Nirmala College for Women \\ Coimbatore-18
}

\author{
J. Pavithra \\ M.Phil Scholar \\ Nirmala College for Women \\ Coimbatore-18
}

\begin{abstract}
In this paper we propose the general bulk service queueing model for $\mathrm{FM} / \mathrm{M}(\mathrm{a}, \mathrm{b}) / 1 / \mathrm{MWV} / \mathrm{Br}$. The batches are served according to FCFS discipline. In which arrival rate, vacation parameter, service rate for busy period, and for vacation period are all considered as trapezoidal fuzzy numbers. The basic idea is to convert all these fuzzy numbers into crisp values by applying Robust ranking Technique. Robust Ranking technique is used to find the expected mean queue length $(\mathrm{Lq}), \mathrm{P}_{\mathrm{v}}$, and $\mathrm{P}_{\text {busy. }}$. Further analytical results of $\mathrm{L}_{\mathrm{q}}, \mathrm{P}_{\mathrm{v}}$ and $P_{\text {busy }}$ are numerically illustrated under crisp environment for the different values of the parameters.
\end{abstract}

\section{Keywords}

Multiple Working Vacation, break down, Mean queue length, Robust Ranking Technique, Fuzzy number.

\section{INTRODUCTION}

In 2002, Servi and Finn introduced a class of semi vacation policies, in which servers work at a lower rate rather than completely stopping primary service during vacation. Such a vacation is called Working vacation (WV). At the vacation termination epochs, if there are customers in the system, the server will start a new regular busy period, otherwise, he takes another working vacation or joins the system and stays idle according as, he follows multiple or single working vacation policy. The M/M/1 queueing system with working vacation has been analysed by Servi and Finn (2002) and Tian .N, Zhao .X and Wang .K (2008a). Zhang and Xu (2008) have analysed the M/M/1 queue with multiple working vacations and N-Policy. Most of the general bulk service queueing models with servers vacation have been analysed by many authors using matrix geometric method. Tian, Li and Zhang (2009) provided a survey of the results of working vacation queues. Moreover, Julia Rose Mary and Afthab Begum (2009) have analysed the Markovian M/M(a,b)/1 queueing model under multiple working vacation and derived the steady state probability distribution and the mean queue length for the model.

The concepts of fuzzy set was first introduced by Zadeh(1965) in his paperwork entitled "fuzzy sets". Fuzzy queueing models have been described by such researchers like Li and Lee (1989). They investigated analytical results for two fuzzy queues using a general approach based on Zadeh's extention principle. Nagi and Lee(1992) proposed a procedure using $\alpha$-cut and two variables simulations to analyse fuzzy queues. Using parametric programming, Kao et al (1993) proposed a general queuing systems in a fuzzy environment based on Zadeh's extension principle. Moreover Kao applied $\alpha$-cut approach to reduce a fuzzy queue into family of crisp queue. Ranking Technique has been discussed by research like Choobinesh and Li (1993), Yager R.R(1981), and Chen,S.P (2005). Ritha and Lilly Robert (2009) have discussed application of fuzzy set theory to queues. Nagoor Gani .A and V. Ashok Kumar(2009) have analysed bulk arrival fuzzy queues with fuzzy outputs. Julia Rose Mary .K and Shanmuha priya (2014) have discussed $\mathrm{FM}_{(\mathrm{m}, \mathrm{n})}^{\mathrm{x}} / \mathrm{G}_{\mathrm{sos}} / 1$ with fuzzy breakdowns and fuzzy multiple vacations. They derived the membership function of total average cost using Zadeh extension principle.

In literature we have many methods for converting fuzzy into crisp for which Robust ranking technique is the most successful and very convenient method for converting fuzzy to crisp values. Palpandi .B and Geedhamani .G (2013)have analysed evaluations of performance measures of bulk arrival queue with fuzzy using Robust Ranking Technique. Julia Rose Mary .K and Angel Jenitta (2014) have studied the cost analysis for bi level threshold policy and single vacation of an unreliable server with fuzzy parameters using Robust ranking technique successively. Recently, Julia Rose Mary .K and Pavithra .J (2016) studied the FM/M(a,b)/1 with multiple working vacations queuing model in Robust Ranking Technique. With the aid of literature available in this paper we apply Robust Ranking Technique, which helps to provide system characteristics of interest in terms of crisp values for bulk arrival queue with fuzzified Poisson arrival rate, service rate, break down rate, and vacation rate.

\section{MODEL DESCRIPTION}

In this model it is assumed that the arrival process is Poisson with parameter $\lambda$. The server processes the customers in batches according to the general bulk service rule(GBSR) introduced by Neuts (1967)

According to this rule the server starts service only when a minimum of ' $\mathbf{a}$ ' customers are present in the system. If the server after a service completion finds a (or) more but at most b customers present in the system, then he takes them all in a batch, and if he finds more than $\mathbf{b}$, then he takes in the batch the first b- customers for service, while others wait. Thus each batch for service contains a minimum of ' $\mathbf{a}$ ' units and a maximum of ' $\mathbf{b}$ ' units. This rule is called general bulk service rule(GBSR). The service time of batches of size $\mathrm{S}(\mathrm{a} \leq \mathrm{s}$ $\leq b)$ is assumed to be independent identically distributed random variable with exponential distribution of parameter $\mu$.

The server is subject to break downs at any time while working, with Poisson rate $\alpha$. Whenever the system fails, the server is sent immediately for repair facility where the repair time is an independent and identically distributed random variable $\mathrm{Br}$ following an exponential distribution $\left(1-e^{-\beta t}\right)$ the customer, who is just being served when the server break down, joins the head of waiting line and resumes the service as soon as the server returns from the repair facility. This type of service continues until the system becomes empty again.

Whenever the server completes a service and finds less than ' $a$ ' customers in the queue he begins a vacation which is an exponentially distributed random variable $\mathrm{V}$ with parameter $\eta$. After completing a vacation, if the system length is still less 
than ' $\mathbf{a}$ ' he takes another vacation and the vacations are continued until the server finds at least ' $\mathbf{a}$ ' customers in the queue (i.e) multiple vacation is adopted. Suppose during vacation if the queue size becomes at least ' $a$ ' the server starts his service under the GBSR with service rate $\mu_{\mathrm{v}}$ which is different from the regular service rate $\mu$. When the vacation ends he switches his service rate from $\mu_{v}$ to $\mu$ when the server is working, the size of the batch in service is $\mathrm{x}$ with $\mathrm{a} \leq \mathrm{x} \leq \mathrm{b}$ and the service rates are independent of the size of the batch in service, The server may breakdown at any time, and it is sent for repair and thus it is completely repaired. Then the service continues his service. The above queueing model is denoted by $\mathbf{M} / \mathbf{M}(\mathbf{a}, \mathbf{b}) / \mathbf{1} / \mathbf{M W V} / \mathbf{B r}$. The steady state results including the probability distribution of the queue size and the expected number of units in the queue are obtained.

Suppose the arrival rate $\lambda$ with Poisson distribution, service rate $\mu$ for busy period, service rate $\mu_{\mathrm{v}}$ for vacation period, vacation parameter $\eta$, Breakdown rate $\alpha$ and repair rate $\beta$. Further, if the minimum number of customers in queue is ' $\mathbf{a}$ ', and a maximum number of customers in the queue is ' $\mathbf{b}$ ' are approximately known. Then we represent the fuzzy set as

$\bar{\lambda}, \bar{\mu}, \bar{\mu}, \bar{\eta}, \bar{\alpha}, \bar{\beta}$

(i.e) $\bar{\lambda}=\left\{t, \theta(t) / \theta_{\bar{\lambda}}(t) / t \in S(\bar{\lambda})\right\}, \bar{\mu}=\left\{x, \underset{\mu}{\theta_{-}}(x) / x \in S(\bar{\mu})\right\}$,

$\bar{\mu}_{v}=\left\{v, \theta_{\mu_{v}}(v) / u \in S\left(\mu_{v}\right)\right\}, \bar{\eta}=\left\{\underset{\eta}{g, \theta_{-}(g) / g \in S(\bar{\eta})}\right\}$,

$\bar{\alpha}=\left\{d, \theta_{\alpha}(d) / d \in S(\bar{\alpha})\right\}, \quad$ and $\quad \bar{\beta}=\left\{w, \theta_{\bar{\beta}}(w) / w \in S(\bar{\beta})\right\}$

Here $\theta_{\mathrm{a}}(\mathrm{b})$ and $\mathrm{S}(\mathrm{a})$ denote the membership function and support of a where $a=\bar{\lambda}, \bar{\mu}, \bar{\mu}, \bar{\eta}, \bar{\alpha}, \bar{\beta}$ are fuzzy numbers and $\mathrm{b}=\mathrm{t}, \mathrm{x}, \mathrm{v}, \mathrm{g}, \mathrm{d}, \mathrm{w}$ are crisp values corresponding to arrival rate, service rate for busy period, service rate for vacation period, vacation parameter, Breakdown rate and repair rate respectively.

On the basis of the concept of $\alpha$-cut we develop a mathematical programming approach for deriving the $\alpha$-cuts of $\bar{\lambda}, \bar{\mu}, \bar{\mu}, \bar{\eta}, \bar{\alpha}, \bar{\beta}$ as crisp intervals which are given by,

$\bar{\lambda}(\alpha)=\left\{t \in T / \theta_{\bar{\lambda}}(t) \geq \alpha\right\}, \bar{\mu}(\alpha)=\left\{x \in X / \theta_{\mu}(x) \geq \alpha\right\}$,

$\bar{\mu}_{v}(\alpha)=\left\{v \in V / \theta_{\mu_{v}}(v) \geq \alpha\right\}, \bar{\eta}(\alpha)=\left\{\underset{\eta}{\left.g \in G / \theta_{-}(g) \geq \alpha\right\}}\right.$,

$\bar{\alpha}(\alpha)=\left\{d \in D / \theta_{\alpha}(d) \geq \alpha\right\}, \bar{\beta}(\alpha)=\left\{w \in W / \theta_{-\beta}(w) \geq \alpha\right\}$

where $0<\alpha \leq 1$. Hence a fuzzy queue can be reduced to a family of crisp queues with difference $\alpha$-cuts as

$\{\lambda(\alpha) / 0<\alpha \leq 1\}, \quad\{\mu(\alpha) / 0<\alpha \leq 1\}, \quad\left\{\mu_{v}(\alpha) / 0<\alpha \leq 1\right\}$,

$\{\eta(\alpha) / 0<\alpha \leq 1\}, \quad\{\alpha(\alpha) / 0<\alpha \leq 1\}, \quad\{\beta(\alpha) / 0<\alpha \leq 1\}$. Let the confidence interval of the fuzzy sets $\lambda(\alpha), \mu(\alpha), \mu_{v}(\alpha), \eta(\alpha), \alpha(\alpha), \beta(\alpha)$ as,

$\left[l_{\lambda}(\alpha) \quad u_{\lambda}(\alpha)\right], \quad\left\lfloor l_{\mu}(\alpha) \quad u_{\mu}(\alpha)\right], \quad\left\lfloor l_{\mu_{v}}(\alpha) \quad u_{\mu_{v}}(\alpha)\right\rfloor$

$\left\lfloor l_{\eta}(\alpha) \quad u_{\eta}(\alpha)\right], \quad\left[\begin{array}{ll}l_{\alpha}(\alpha) & u_{\alpha}(\alpha)\end{array}\right], \quad\left\lfloor l_{\beta}(\alpha) \quad u_{\beta}(\alpha)\right\rfloor$

.Then the expected queue length $(\mathrm{Lq})$ is given as,
$L q=A H(r, \mu)+B H\left(r_{v}, \mu\right)+H\left(r_{v}, \mu_{v}\right)+A J(r, \alpha)+B J\left(r_{v}, \alpha\right)$

Where $H(x, y)=\frac{x}{(1-x)^{2}}+\frac{y}{\lambda(1-x)}\left\{\frac{a(a-1)}{2}+\frac{a x^{a+1}(1-x)-x^{2}\left(1-x^{a}\right)}{(1-x)^{2}}\right\}$

and $J(x, y)=\frac{x}{(1-x)^{2}}\left[\frac{x y}{\lambda(x-1)+\beta x}\right]$

with $A=\left[\frac{\mu\left(1-r^{a}\right)}{(1-r)}-\frac{\alpha \beta r}{\lambda(r-1)+\beta r}\right]^{-1}\left[\frac{\eta}{\left(1-r_{v}\right)}-\frac{B \mu\left(1-r_{v}^{a}\right)}{\left(1-r_{v}\right)}+\frac{\alpha \beta B r_{v}}{\lambda\left(r_{v}-1\right)+\beta r_{v}}\right]$

$B=\frac{\eta r_{v}\left(\lambda\left(r_{v}-1\right)+\beta r_{v}\right)}{\left[\lambda\left(r_{v}-1\right)+\mu r_{v}\left(1-r_{v}^{b}\right)+\alpha r_{v}\right]\left[\lambda\left(r_{v}-1\right)+\beta r_{v}\right]-\alpha \beta r_{v}^{2}}$

In the above formula by applying the fuzzy variable for arrival rate, service rate for busy, service rate for vacation, vacation parameter, Breakdown rate, repair rate then we get,

The expected queue length (Lq) is given as

$L q=A H(r, x)+B H\left(r_{v}, x\right)+H\left(r_{v}, v\right)+A J(r, d)+B J\left(r_{v}, d\right)$

where $H(x, y)=\frac{x}{(1-x)^{2}}+\frac{y}{\lambda(1-x)}\left\{\frac{a(a-1)}{2}+\frac{a x^{a+1}(1-x)-x^{2}\left(1-x^{a}\right)}{(1-x)^{2}}\right\}$

and $\quad J(x, y)=\frac{x}{(1-x)^{2}}\left[\frac{x y}{t(x-1)+w x}\right]$ with

$A=\left[\frac{x\left(1-r^{a}\right)}{(1-r)}-\frac{d w r}{t(r-1)+w r}\right]^{-1}\left[\frac{g}{\left(1-r_{v}\right)}-\frac{B x\left(1-r_{v}^{a}\right)}{\left(1-r_{v}\right)}+\frac{d w B r_{v}}{t\left(r_{v}-1\right)+w r_{v}}\right]$

$B=\frac{g r_{v}\left(t\left(r_{v}-1\right)+w r_{v}\right)}{\left.\left.t t\left(r_{v}-1\right)+x r_{v}\left(1-r_{v}^{b}\right)+w r_{v}\right\rfloor t\left(r_{v}-1\right)+w r_{v}\right]-d w r_{v}^{2}}$

\section{ROBUST RANKING TECHNIQUE}

To find the characteristics of system interest in terms of crisp value we defuzzyify the numbers into crisp ones by a fuzzy number ranking method. Robust ranking technique by Nagarajan \& Solai Raju (2010) satisfies compensation, linearity and additive properties results which are consistent with human intuition. By giving a convex fuzzy number a, the Robust Ranking index is defined by,

$R(\bar{a})=\int_{0}^{1} 0.5\left(a_{\alpha}^{L}+a_{\alpha}^{U}\right) d \alpha$ where $\left(a_{\alpha}^{L}+a_{\alpha}^{U}\right)$ is the $\alpha$-level cut

of the fuzzy number $\bar{a}$. In this paper we use the method for ranking the fuzzy numbers. The Robust ranking index $R(\bar{a})$

gives the representative value of the fuzzy number $\bar{a}$. It Satisfies the linearity and additive property.

\section{NUMERICAL EXAMPLE}

In this section numerical results are calculated under fuzzy and crisp environment.

\subsection{Fuzzy Environment}

Consider fuzzy M/M(a,b)/1/MWV with break down queueing system. The corresponding parameters such as arrival rate, service rate for busy, service rate for vacation, vacation parameter, Breakdown rate, repair rate are fuzzy numbers. Let us consider the parameters us,

$$
\begin{aligned}
& \lambda=[0.2,0.3,0.4,0.5], \quad \mu=[0.05,0.015,0.025,0.035], \\
& \mu_{v}=[0.02,0.04,0.06,0.08], \quad \eta=[0.01,0.02,0.03,0.04], \\
& \alpha=[0.02,0.04,0.06,0.08], \quad \beta=[0.1,0.2,0.3,0.4]
\end{aligned}
$$


Whose intervals of confidence are $\left[\begin{array}{ll}0.2+\alpha & 0.5-\alpha\end{array}\right],[0.05+\alpha \quad 0.35-\alpha],\left[\begin{array}{ll}0.02+\alpha & 0.08-\alpha\end{array}\right]$, $[0.01+\alpha \quad 0.04-\alpha],\left[\begin{array}{ll}0.02+\alpha & 0.08-\alpha\end{array}\right]$ and $\left[\begin{array}{ll}0.1+\alpha & 0.4-\alpha\end{array}\right]$ respectively.

Now we evaluate $\mathrm{R}(0.2,0.3,0.4,0.5)$ by applying Robust Ranking Method. The membership function of the trapezoidal fuzzy number $\quad(0.2,0.3,0.4,0.5) \quad$ is,

$R(\bar{\lambda})=R(0.2,0.3,0.4,0.5)$

$=\int_{0}^{1} 0.5(0.2+0.5) d \alpha=\int_{0}^{1} 0.5(0.7) d \alpha=0.35$

$R(\bar{\mu})=R(0.05,0.15,0.25,0.35)$

$=\int_{0}^{1} 0.5(0.05+0.35) d \alpha=\int_{0}^{1} 0.5(0.4) d \alpha=0.2$

By proceeding similarly the Robust Ranking indices for the fuzzy numbers $\bar{\lambda}, \bar{\mu}, \bar{\mu}, \bar{\eta}, \bar{\alpha}, \bar{\beta}$ are calculated as $R(\bar{\mu})=0.2, R\left(\bar{\mu}_{v}\right)=0.05, R(\bar{\eta})=0.025, R(\bar{\alpha})=0.05$ and $R(\bar{\beta})=0.25$.

By considering the parameters as,

$\mu=0.2, \quad \lambda=0.35, \quad \alpha=0.05, \quad \beta=0.25, \quad r=0.8, \quad r_{v}=0.9, \quad \mu_{v}=0.05, \quad b=15$ the values are calculated. Calculated values are tabulated and it is represented in the following graph.

Table 1: Mean queue length for $\mathrm{FM} / \mathrm{M}(\mathrm{a}, \mathrm{b}) / 1 / \mathrm{MWV} / \mathrm{Br}$ model.

\begin{tabular}{|l|r|r|r|r|r|}
\hline $\mathbf{a}$ & $\mathbf{0 . 0 2 5}$ & $\mathbf{0 . 0 5}$ & $\mathbf{0 . 0 7}$ & $\mathbf{0 . 1}$ & $\mathbf{0 . 1 2 5}$ \\
\hline 5 & 131.45 & 167.79 & 197.36 & 241.27 & 277.9 \\
\hline 6 & 136.79 & 175.33 & 206.26 & 252.56 & 291.16 \\
\hline 7 & 143.62 & 184.59 & 217.377 & 266.52 & 291.16 \\
\hline 8 & 152.65 & 197 & 232.39 & 285.55 & 331.67 \\
\hline 9 & 163.21 & 211.07 & 249.35 & 306.76 & 354.63 \\
\hline 10 & 244.34 & 330.87 & 400.11 & 503.88 & 590.46 \\
\hline
\end{tabular}

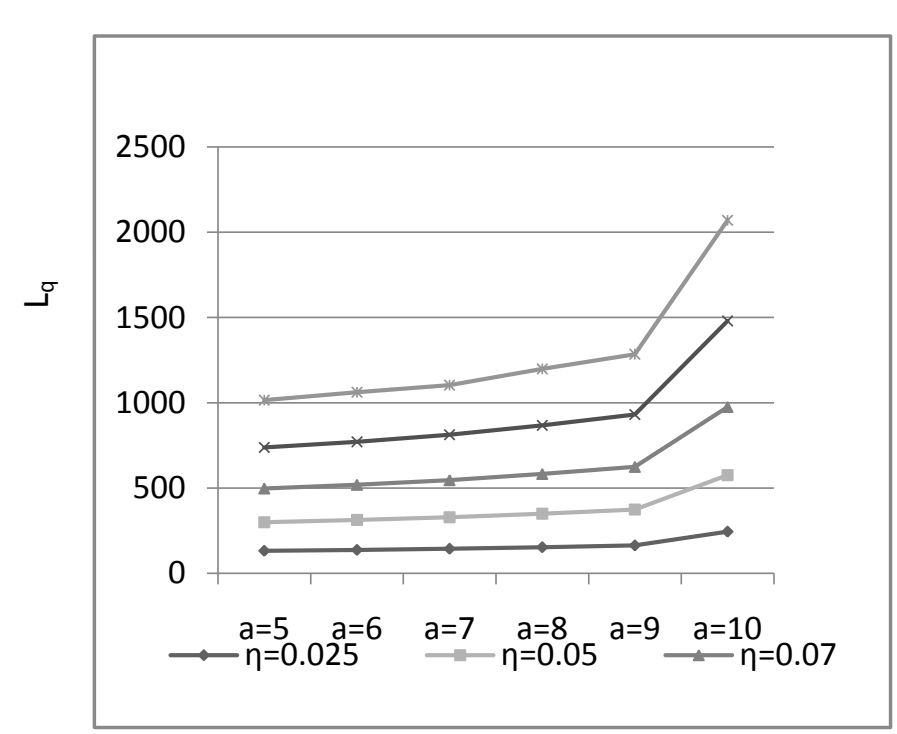

Graph(1). Lq versus (a, $\eta)$

From the table (1) and figure (1), we find that, the mean queue length $\mathrm{Lq}$ increases when the vacation parameter increases. Also, we find that the mean queue length $(\mathrm{Lq})$ increases when the batch size increases. For FM/M(a,b)/MWV/Br Model.

\subsection{Crisp Enviroment}

In order to explore the effect of various system parameters on the performance measure, numerical evaluation is performed and the various results are displayed with graphs.

Assume that the arrival time, service rate for busy period, service rate for vacation period, vacation parameter, Breakdown rate, repair time follow exponential distribution with respective rates $\lambda, \mu, \mu_{v}, \eta, \alpha$ and $\beta$.

Now the probability that the system is in vacation $\left(\mathrm{P}_{\mathrm{v}}\right)$ and the probability that the system is in busy state $\left(\mathrm{P}_{\text {busy }}\right)$ are evaluated.

For computation purpose we arbitrarily choose the parameters as, $\lambda=0.4, \mu=0.2, \mu_{v}=0.05, b=15, r=0.8, r_{v}=0.9, a=5, \eta=0.025$, $\alpha=0.05, \beta=0.25$.

The Performance measures $\mathrm{P}_{\mathrm{v}}$-the probability that the system is vacation and $\mathrm{P}_{\text {busy }}$ - the probability that the system is busy are evaluated and also displayed in graph (2) and (3).

Table.2: probability that the system is in vacation $\left(\mathbf{P}_{\mathrm{v}}\right)$

\begin{tabular}{|c|c|c|c|c|c|}
\hline $\boldsymbol{\mu}_{\mathbf{v}}$ & 0.05 & 0.1 & 0.15 & 0.2 & 0.25 \\
\hline 0.025 & 0.1794 & 0.1743 & 0.1694 & 0.1649 & 0.1605 \\
\hline 0.05 & 0.1643 & 0.1600 & 0.1559 & 0.1520 & 0.1483 \\
\hline 0.07 & 0.1516 & 0.1479 & 0.1444 & 0.1410 & 0.1378 \\
\hline 0.1 & 0.1406 & 0.1375 & 0.1344 & 0.1315 & 0.1287 \\
\hline 0.125 & 0.1312 & 0.1284 & 0.1258 & 0.1232 & 0.1208 \\
\hline 0.15 & 0.1229 & 0.1205 & 0.1181 & 0.1159 & 0.1137 \\
\hline
\end{tabular}




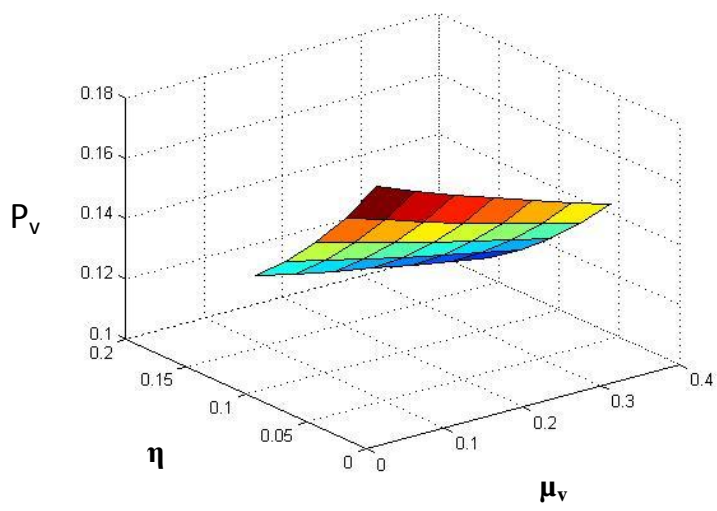

$\operatorname{Graph}(2) . P_{v}$ versus $\left(\mu_{v}, \eta\right)$

The combined effect of $\mu_{\mathrm{v}}$ and $\eta$ are presented in $\operatorname{Graph}(2)$, we observe that $\mathrm{Pv}$ decreases when service in vacation $\operatorname{state}\left(\mu_{v}\right)$ and vacation parameter $(\eta)$ increases.

Now $\mathrm{P}_{\text {busy }}$ is evaluated with respect to $\eta$ and $\mu_{v}$.

Table.3: probability that the system is in busy state $\left(\mathbf{P}_{\text {busy }}\right)$

\begin{tabular}{|l|l|l|l|l|l|}
\hline \multicolumn{1}{|c|}{$\boldsymbol{\mu}_{\mathrm{v}}$} & 0.05 & 0.1 & 0.15 & 0.2 & 0.25 \\
\hline 0.025 & 0.8691 & 0.8442 & 0.8207 & 0.7985 & 0.7774 \\
\hline 0.05 & 0.8277 & 0.8059 & 0.7853 & 0.7657 & 0.7470 \\
\hline 0.075 & 0.7927 & 0.7735 & 0.7551 & 0.7376 & 0.7209 \\
\hline 0.1 & 0.7628 & 0.7456 & 0.7291 & 0.7134 & 0.6983 \\
\hline 0.125 & 0.7369 & 0.7214 & 0.7065 & 0.6922 & 0.6784 \\
\hline 0.15 & 0.7143 & 0.7002 & 0.6866 & 0.6735 & 0.6609 \\
\hline
\end{tabular}

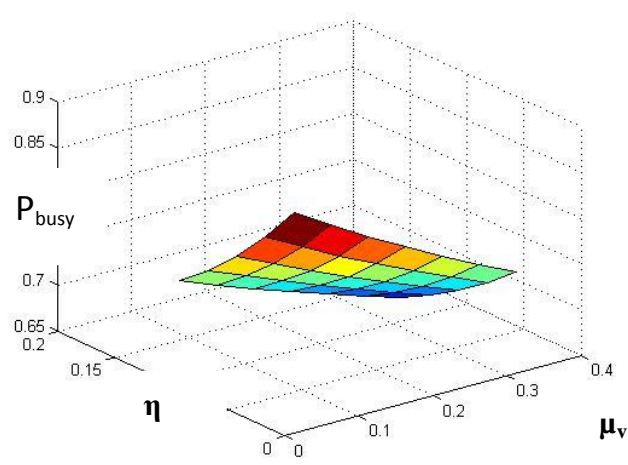

$\operatorname{Graph}(3) \mathbf{P}_{\text {busy }}$ versus $\left(\mu_{v}, \eta\right)$

From the table (3) and $\mathrm{Graph}(3)$, we find that $\mathrm{P}_{\text {busy }}$ decreases when $\mu_{v}$ and $\eta$ increases.

\section{CONCLUSION}

In this paper fuzzy set theory has been applied to bulk service queueing model with Poisson arrival. The arrival rate, service rate for busy period, service rate for vacation period, repair rate and vacation parameter are fuzzy number which are more realistic and general in nature. Moreover by using Robust Ranking Technique the fuzzy problem has been converted into crisp problem and also we notice that by applying Robust Ranking Technique the solution of fuzzy problem becomes more efficient.

\section{REFERENCES}

[1] Chen, S.P (2005) "Parametric nonlinear Programming approach to fuzzy queues with bulk service", European Journal of Operational Research, Vol.163,pp.434-444

[2] Choobinesh, F and Li, H (1993), "An index for ordering fuzzy numbers", Fuzzy numbers and system,Vol 54, pp.143-161.

[3] Julia Rose Mary .K and Afthab Begum .M (2009)," Closed form Analytical solution of the General Bulk service queueing model $\mathrm{M} / \mathrm{M}(\mathrm{a}, \mathrm{b}) / 1$ under working vacation", International conference on Mathematical and Computational models, PSG College of Tech. 92-100.

[4] Julia Rose Mary .K and Angel Jenitta (2014), "Evaluation of total average cost of $\mathrm{MX}(\mathrm{m}, \mathrm{N}) / \mathrm{M} / 1 / \mathrm{BD} / \mathrm{SV}$ with fuzzy parameter using Robust Ranking Technique”, National Annual Research Congress.

[5] Julia Rose Mary .K and Shanmugapriya (2014),“ Optional operating policy of $\operatorname{FMX}(\mathrm{m}, \mathrm{N}) / \mathrm{GSOS} / 1 / \mathrm{MV}$ ", International journal of computer Application, vol 1,issued 4,pp.199-207.

[6] Julia Rose Mary .K and Majula Christina (2015), "Evaluation of total average cost of $\mathrm{MX}(\mathrm{m}, \mathrm{N}) / \mathrm{M} / 1 / \mathrm{BD} / \mathrm{MV}$ with fuzzy parameters using Robust Ranking Technique", International journal of Computer Application, vol.121-No.24.,pp.1-4.

[7] Julia Rose Mary .K and Pavithra .J (2016), "Analysis of FM/M(a,b)/1/MWV queueing model. International Journal of Innovative Research in Science. Engineering and Technology. Vol.5 issue 2, pp.1391-1397.

[8] Kao, C., Li, C., and Chen,S., (1993), "Parametric programming to the analysis of fuzzy queues", Fuzzy sets and system, vol.107, pp.93-100

[9] Li, R.J., and Lee, E.S., (1989), "Analysis of fuzzy queues, Computers and Mathematics with applications, vol.17(7), pp.1143-1147.

[10] Nagarajan \& Solairaju (2010), "Computing Improved fuzzy optimal Hungarian assignment problems with fuzzy costs under Robust Ranking Techniques", vol.6, no.13, pp.6-13.

[11] Nagi, D.S., and lee, E.S., (1992), "Analysis and simulation of fuzzy queues", Fuzzy sets and systems, vol.46, pp.321-330.

[12] Neuts M.F., (1967), "A general class of bulk queues with poisson input”,Ann.Math.Statist., Vol.38,pp.759-770.

[13] [Nagoor Gani .A and Ashok kumar .v (2009), “A bulk arrival queueing model with fuzzy parameters and fuzzy varying batch size", BPAS Research, vol.2,no.333.

[14] Palpandi .B, Geethamani .G (2013), "Evaluation of Performance of bulk arrival queue with fuzzy parameters using Robust Ranking Technique", International journal of computing Engineering research, vol.03, issue 10, pp.53-57.

[15] Ritha and Lilly Robert (2009), “ Application of fuzzy set theory to queues", International Journal of Computing and Mathematics, International Journal of Algorithms, Computing and Mathematics, vol.2, no.4. 
[16] Servi, LD., and Finn, S.G., (2002) "M/M/1 queues with working vacations(M/M/1/WV)", Performance Evauation,Vol.50,pp. 41-52, 2002.

[17] Tian, N., Zhao, X., and Wang, K., "The M/M/1 queue with single working vacation", International Journal of Information Management Sciences, Vol.19, pp.621-634, 2008a.

[18] Tian, N., Li, J., and Zhang, G., "Matrix analytic method and working vacation queue-A survey", International Journal of Information Management Sciences,Vol.20,pp.603-633, 2009.
[19] Yager, R.R (1981) “A Procedure for Ordering fuzzy subsets of the unit interval, Information Sciences, vol.24, pp.143-161

[20] Zadeh, (1965), "Fuzzy Sets", Information and Control, Vol 5(3), pp:338.

[21] Zhang Z., and $\mathrm{Xu}, \mathrm{X}$., "Analysis for the $\mathrm{M} / \mathrm{M} / 1$ queue with multiple working vacations and $\mathrm{N}$ - Policy", Information and Management services, Vol.19(3),pp.495506, 2008. 